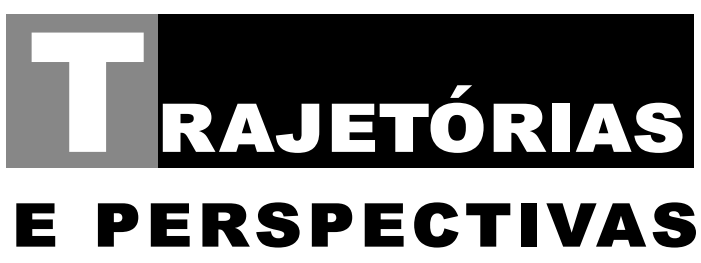




\section{Para cima, Antropólogos: perspectivas ganhas em estudar os de cima}

\section{Up the Anthropologist: perspectives gained from studying up}

\section{Laura Nader}

Estados Unidos. Universidade de Berkeley. Professora do Departamento de Antropologia da Universidade de Berkeley e integra a Academia Americana de Artes e Ciências. Ph.D em Antropologia pelo Radcliffe College.E-mail: lanad@berkeley.edu.

\section{Tradução de Mirian Alves e Wellington Santos}

\section{Mirian Alves}

Brasil. Universidade Federal Fluminense. Doutora em Antropologia, professora do Departamento de Antropologia da Universidade Federal Fluminense e do Programa de Pós-Graduação em Justiça e Segurança. Pesquisadora do Núcleo de Estudos do Oriente Médio e do Instituto de Estudos Comparados em Administração de Conflitos. ID ORCID: https://orcid.org/0000-0001-7153-9335. E-mail: mirian.uff@gmail.com. Colaboração: Tradução, redação e revisão.

\section{Wellington Santos}

Brasil. Universidade Federal Fluminense. Graduando do curso de Antropologia da Universidade Federal Fluminense, em fase de conclusão. Pesquisador do Núcleo Fluminense de Estudos e Pesquisas e do Laboratório de Etnografia Metropolitana. ID ORCID: https://orcid.org/0000-0003-2747-7274.

E-mail:wellington_marcello@id.uff.br. Colaboração: Tradução, redação e revisão.

\section{Resumo}

Neste ensaio, descreverei algumas das oportunidades que os antropólogos têm de "estudar os de cima" (studying up) em sua própria sociedade, na expectativa de fomentar mais discussões sobre o porquê estudamos o que estudamos (NADER, 1964). Os antropólogos têm uma grande contribuição para a nossa compreensão dos processos pelos quais o poder e a responsabilidade são exercidos nos Estados Unidos. Além disso, há uma certa urgência para esse tipo de antropologia preocupada com o poder (Cf. WOLF, 1969), pois a qualidade de vida e as nossas próprias vidas em si mesmas dependem do modo como os cidadãos compreendem aqueles que moldam e realmente controlam as estruturas institucionais. O estudo 
do homem é confrontado com uma situação sem precedentes: nunca antes tão poucos, por suas ações e inações, tiveram o poder de vida e morte sobre tantos membros da espécie humana. Apresento três razões para "estudar os de cima": seu efeito estimulante e articulador para muitos estudantes, adequação científica e relevância democrática do trabalho científico. Finalmente, considerarei alguns obstáculos e objeções frequentes e tentarei respondê-los.

Palavras-chave: "de cima”, elite, antropologia reinventada, poder.

\section{Abstract:}

In this essay I describe some opportunities that anthropologists have for "studying up" in their own society, hoping to generate further discussion on the purpose of our studies (NADER, 1964). Anthropologists can contribute greatly to our understanding of the processes whereby power and responsibility are exercised in the United States. Moreover, there is a certain urgency for this kind of anthropology that is concerned with power (Cf. WOLF, 1969), for the quality of life and our lives themselves may depend on the extent to which citizens understand those who shape attitudes and effectively control institutional structures. The study of humans is confronted with an unprecedented situation: never before have so few, regardless of by action or inaction, had the power of life and death over so many members of the species. I present three reasons for "studying up": its energizing and integrating effect for many students; its scientific adequacy; and the democratic relevance of such scientific work. Lastly, I consider common obstacles and objections to this argument and propose some counter-arguments.

Keywords: "studying up", elite, reinventing anthropology, power.

\section{INDIGNAÇÃO COMO MOTIVAÇÃO}

Muitos de nossos estudantes mais brilhantes olham para as revistas de antropologia dos últimos tempos e concluem que a antropologia parece estar em fase de extinção, contentando-se em ganhar a vida em grande parte ou redescobrindo o que já havia sido descoberto ou vendendo suas mercadorias para outras 
disciplinas e profissões. A audiência é restrita demais e as minúcias preciosas demais. Ganhar a vida vendendo suas mercadorias não é uma maneira inadequada de subsistir; é, no entanto, neste caso, sintomático que um talento, a perspectiva de um Espelho para o Homem (Mirror for Man), esteja sendo subutilizado.

Hoje temos estudantes de antropologia que estão indignados com muitos problemas que afetam o futuro do Homo sapiens, mas eles estão estudando problemas sobre os quais não têm "sentimentos". Alguns acham que essa éa única postura apropriada para uma ciência. No entanto, os estudantes não estão estudando os assuntos que os animam. Eu acho que estamos perdendo alguma coisa aqui. O impulso normativo muitas vezes nos leva a fazer perguntas importantes sobre um fenômeno que não seriam feitas de outra maneira, ou a definir um problema em um novo contexto. Um rápido crescimento nos estudos de direitos civis é diretamente atribuível a atividades pelas quais as vítimas do sistema tornam visível a própria vitimização. Por um processo de contágio, essa visibilidade espalhou a indignação moral para as faculdades de direito e para a profissão jurídica, o que, por sua vez, levou à pesquisa de questões civis e sobre a área correlata da lei da pobreza. Na antropologia, temos o exemplo de Crisântemo e a Espada, de Ruth Benedict (1946), um esforço para entender os oponentes na guerra. O impulso normativo aqui, gerado pelo patriotismo e pela lealdade, considerado apropriado na Segunda Guerra Mundial, foi responsável por um livro perspicaz e pelo desenvolvimento de novas técnicas para estudar a cultura a distância.

Ao relembrar um dos primeiros fundadores da antropologia americana, L. H. Morgan (o primeiro antropólogo a se tornar presidente da American Association for the Advancement of Society), descobrimos que ele abriu novos caminhos na ciência por ter se interessado por um problema social (RESEK, 1960). Ao longo de sua carreira, Morgan ficou indignado com o tratamento dado aos índios americanos, que estavam sendo expulsos de suas terras. Foi sua indignação inicial, que precedeu sua curiosidade sobre sistemas de parentesco e estrutura social, que o levou a estudar os índios americanos. No caso de Morgan, a indignação teve um efeito estimulante. 
Como Jules Henry (1963, p. 46, tradução nossa) coloca:

Pensar profundamente em nossa cultura é se enfurecer e enfurecer os outros: e, caso, você não consiga tolerar essa fúria, estará desperdiçando o tempo que gasta pensando profundamente. Uma das recompensas do pensamento profundo é o brilho quente da fúria ao descobrir um erro, mas, se a fúria for um tabu, o pensamento definhará até a morte.

Eu vejo entre os jovens alunos em Berkeley um fenômeno estimulante no estudo das principais instituições e organizações que afetam a vida cotidiana, como a California Insurance Comission, O Better Business Bureau (BBB), agências de poluição atmosférica e similares. Os seguintes excertos extensos ilustram o que motivou esses alunos a levar a cabo seus estudos.

Escolhi estudar o setor de seguro principalmente porque é uma daquelas "coisas" (não há um termo) que são feitas de vastas redes de pessoas que influenciam muitos aspectos da vida de todas as pessoas na Califórnia. A maioria é afetada diretamente, por possuir uma apólice de seguro. Todos são afetados de outras maneiras, tais como a vasta influência política do "setor de seguros" e sua enorme influência econômica em nossas vidas pessoais.

Por exemplo, alguém vai ao mercado no seu próprio carro, que está segurado. O Mercado em que chega está segurado por perda, roubo, danos e risco. A comida foi entregue por caminhões que tinham seguro para a carga transportada, que também estava protegida contra vários problemas. O preço dessas coberturas também afeta o preço da sua comida. Incidentalmente, as fábricas onde o caminhão e seu automóvel foram fabricados contam com várias apólices de seguro (assim como todos os funcionários). Uma delas, chamada de "seguros contra poluição", protege a empresa por passivos incorridos caso seja processada por danos causados pela poluição. O preço disso afeta os outros preços, como mencionado, mas o fato de ter uma apólice de seguro permite que o fabricante ou a rede de pessoas que controla a fábrica polua o ar sem incorrer em risco econômico. Indo mais além, a montadora provavelmente pertence, em grande parte, a seguradoras. Para se ter uma ideia da enorme riqueza do setor de seguros, considere que os segurados da Califórnia pagaram mais de US $\$ 6$ bilhões em prêmios de seguros em 1970 , o que dá mais de US $\$ 300$ por pessoa no 
Estado da Califórnia. Isso mais do que a renda per capita da maioria da população mundial. De fato, o montante anual dos prêmios recebidos pelo setor de seguros nos EUA só não é maior do que o produto interno bruto de cinco nações em todo o mundo (SERBER, 1971, p. 2-3, tradução nossa).

Outra aluna teve o seguinte a dizer sobre seu estudo do Oakland BBB:

Em nossa complexa sociedade, obtemos muitos bens e serviços pré-embalados. Como no famoso caso da criança da cidade que acredita que o leite cresce em caixas de papelão, a maioria dos consumidores pouco sabe sobre a composição dos produtos comprados, como eles funcionam, como avaliar seu potencial antes de comprá-los, e como consertá-los caso quebrem. Essa ignorância não se limita aos bens, mas se estende a serviços, investimentos, instituições de caridade, para não falar das profissões jurídicas e médicas. Contamos com a Pacific Gas and Electricity para instalar equipamentos de gás, para verificar sua segurança, e até mesmo para reacender a chama piloto que se apagou acidentalmente, caso não consigamos localizá-la. Levamos nossas roupas especiais para uma tinturaria. Quando a transmissão do automóvel não funciona, o carro deve ser rebocado até um especialista em transmissão. As mercadorias são encomendadas por telefone ou pelo correio. Um vendedor de porta em porta pode vender sessões em um estúdio fotográfico, cosméticos, assinaturas de revistas e investimentos, bem como angariar contribuições para instituições de caridade. Quando quer comprar um tapete, o consumidor depende de um vendedor que explique as qualidades das fibras, calcule a metragem necessária para cobrir uma determinada área e garanta que acessórios como forração, presilhas e mão-de-obra estão incluídos no custo de instalação cotado. Dependemos de especialistas para prestar serviços e, muitas vezes, até mesmo para nos fornecer os critérios pelos quais devemos julgar seu trabalho. Muitas de nossas transações ocorrem com pouca frequência, o que significa que o consumidor pode ser totalmente inexperiente na avaliação do que ele paga quando compra um grande aparelho doméstico, uma apólice de seguro ou uma viagem de férias.

Da mesma forma, ele pode se ver incapaz de obter compensação por suas reclamações quando acha que foi enganado ou trapaceado. A maioria dos contatos com empresas limita-se à voz incorpórea do 
telefonista, à secretária ou ao representante de relações públicas no serviço de atendimento ao cliente ou ao vendedor que, por acaso, está ali na frente quando o cliente entra na loja. O consumidor telefona para a empresa para ver o que vai fazer por ele, ou escreve para a coluna de reclamações de um jornal ou telefona para um programa de rádio. Os serviços desses facilitadores também são "pré-embalados": o reclamante envia sua história e aguarda para que a máquina processe uma resposta, situação que se estende até mesmo às organizações responsáveis pela segurança pública e de defesa dos seus direitos, às quais o consumidor furioso pode acabar prestando sua queixa.

Comecei este projeto sem saber nada sobre o que é o BBB, o que ele faz ou não e por quê. Como um cidadão típico, comecei sabendo apenas que há uma organização apoiada por empresas chamada Better Business Bureau que costuma ser contatada por telefone quando uma pessoa tem uma pergunta sobre a confiabilidade (ou existência!). Poucas pessoas vão além desses fatos e perguntam quem é a voz do outro lado da linha, onde ela obtém suas informações, ou o que realmente acontece com o formulário de reclamação que chega, é devolvido e cujos resultados são encaminhados ao consumidor pelo correio. E ainda assim milhares de pessoas usam o BBB todos os anos (EATON, 1971, p. 2-3, tradução nossa).

Talvez essas sejam tentativas de espiar por trás do anonimato de uma sociedade burocrática, para revelar os mecanismos usados por empresas distantes e indústrias de grande escala para direcionar aspectos cotidianos das nossas vidas. Qualquer que seja a motivação, os estudos levantam questões importantes, como deveres, responsabilidade, autorregulação ou, em outro nível, questões relativas a estrutura social, análise de redes, pesquisa bibliotecária e observação participante.

\section{ADEQUAÇÃO CIENTÍFICA}

Se olharmos para a literatura baseada no trabalho de campo nos Estados Unidos, encontramos uma literatura relativamente abundante sobre os pobres, os grupos étnicos, os desfavorecidos; há relativamente pouca pesquisa de campo sobre a classe média e muito pouco trabalho sobre as classes superiores. 
Os antropólogos podem, de fato, se perguntar se a totalidade do trabalho de campo não depende de uma certa relação de poder em favor do antropólogo e se, de fato, tais relações dominantes-subordinadas podem estar afetando os tipos de teorias que estamos tecendo. E se, ao reinventar a antropologia, os antropólogos estudassem os colonizadores em vez dos colonizados, a cultura do poder e em vez da cultura do impotente, a cultura da influência e não aquela cultura da pobreza?

Estudar os "de cima", assim como "de baixo", nos levaria a fazer muitas perguntas de "senso comum" ao contrário. Em vez de perguntar porque algumas pessoas são pobres, perguntamos: por que outras pessoas são tão abastadas. Como um cientista social poderia explicar os padrões de acumulação dos americanos ricos e da classe média? Como podemos explicar a fantástica resistência à mudança entre aqueles cujas opções "parecem ser muitas"? Como isso aconteceu, podemos nos perguntar, por que os antropólogos estão mais interessados em saber por que os camponeses não mudam do que por que a indústria automobilística não inova, ou por que o Pentágono ou as universidades não podem ser mais criativos organizacionalmente? O conservadorismo de tais grandes instituições e organizações burocráticas provavelmente tem implicações mais amplas para a espécie humana e para as teorias da mudança do que o conservadorismo do campesinato.

Se, ao reinventarmos a antropologia, estivéssemos estudando principalmente os estratos mais poderosos da sociedade urbana, nossa visão do gueto poderia ser, em grande parte, em termos de relações maiores do que o gueto. Estudaríamos os bancos e o setor de seguros que delimitam áreas da cidade para as quais não venderão seguros nem concederão crédito. Estudaríamos a classe de proprietários de imóveis que "recompensa" ou "influencia" agentes da segurança pública ou da fiscalização municipal para que os códigos de obras e edificações não sejam cumpridos. As favelas são tecnicamente ilegais; se os códigos de obras e edificações e outras leis municipais fossem cumpridos, nossas favelas não seriam favelas (se a fiscalização fosse bem-sucedida), ou elas poderiam ser chamadas por outro nome que indicaria que elas são resultado de crimes do colarinho branco. Pode-se dizer que, se esses crimes forem bem-sucedidos, produzirão criminalidade de rua. Com essa perspectiva do crime do colarinho branco, nossa análise da delinquência de gangues pode ser 
correspondentemente afetada e, ao desenvolvermos teorias sobre o comportamento de gangues de favela, poderíamos perguntar: é suficiente entender as gangues apenas como produtos dos sistemas de valores dessa subcultura? Podemos estudar os sistemas de marketing ou o sistema de transporte que, como em Watts, faz de algumas áreas do gueto ilhas virtuais. Podemos estudar o grau em que as práticas jurídicas, ou os tipos de serviços jurídicos, moldam as percepções da lei presentes nos guetos.

As consequências de não se estudar os de cima tanto quanto os de baixo são sérias em termos de desenvolvimento de teorias e descrições adequadas. Se o ponto de articulação de alguém se encontra ao redor daqueles que têm responsabilidade em virtude do poder que lhes é delegado, então as questões mudam. A partir de tal perspectiva, percebem-se diferentes facetas da cultura: o gueto pode ser visto como desprovido de lei, sem lei. Os tribunais não são voltados para as reclamações dos pobres (que se situariam na faixa entre 20 a 80 dólares); além disso, não são voltados para a resolução rápida e barata de conflitos - características cruciais para os pobres. A partir dessa perspectiva, pode-se dizer que as comunidades do gueto são excluídas do sistema legal, exceto como réus, e, na verdade, muitas vezes são excluídas de outros serviços municipais, desde a coleta de lixo até a proteção policial. A partir desta orientação, portanto, a questão que pode ser levantada novamente - em nossos estudos sobre delinquência, é suficiente entender as gangues como produtos dos sistemas de valores apenas dessa subcultura?

Vamos fazer outra pergunta: quais foram as consequências da pesquisa em ciências sociais sobre a criminalidade? Em virtude do nosso foco nos crimes da classe baixa, ajudamos na definição pública de "problema da lei e da ordem" em termos de crimes de rua ou da classe baixa. Vamos supor que o contribuinte público em uma democracia, depois de ouvir um discurso presidencial pedindo mais verba de impostos para a vigilância e a proteção contra a criminalidade de rua, decida analisar a questão por si mesmo. Não importa a que biblioteca ele for, o máximo que ele conseguirá obter é alguma informação sobre crimes cometidos pela classe baixa. Ele não teria como avaliar, dados os materiais descritivos atuais, se, em uma situação de verba limitada, 
seria melhor investir os recursos para combater a criminalidade de rua ou os crimes do colarinho branco que em ambos os casos põem em risco a vida de todos os contribuintes, todos os dias, de várias maneiras.

Como Clyde Mitchell observou, foi com tal problema em mente que os antropólogos introduziram pela primeira vez o conceito de "campo social”.

O estudo antropológico clássico escolhe uma unidade - uma "tribo" ou "sociedade" ou "comunidade" - e apresenta o comportamento de seus membros em termos de uma série de instituições, estruturas, normas e valores interligados. Não são apenas os antropólogos que trabalham em áreas urbanas que acharam este tipo de premissa difícil de manter, mas também aqueles que têm conduzido estudos "tribais" na África moderna (e presumivelmente também em outros lugares). Eles descobriram que o efeito de grupos e instituições que não estão fisicamente presentes na área tribal influencia o comportamento das pessoas que nela se encontram. A unidade de relacionamentos em interação, em outras palavras, é maior do que a tribo (MITCHELL, 1966, p. 56, tradução nossa).

Lowie pode ter estudado os Crow, Llewellyn e Hoebel os Cheyenne, como se fossem "ilhas" não relacionadas à sociedade mais ampla e até mesmo não relacionadas com as políticas e ações do Escritório de Assuntos Indígenas, mas há uma literatura inteira desde a década de 1950 desafiando a visão de mundo limitada da comunidade etnográfica e o reconhecimento de uma necessidade metodológica foi, como observou Mitchell, o que talvez tenha estimulado o desenvolvimento da teoria de redes e o desenvolvimento dos estudos sobre o estado-nação (ADAMS, 1970).

Se a antropologia fosse reinventada para estudar os de cima, cedo ou tarde precisaríamos estudar os de baixo também. Não estamos lidando com uma proposta que exclui outras opções; precisamos simplesmente perceber quando é útil ou crucial, em termos do problema, ampliar o domínio do estudo para cima, para baixo ou para os lados. Se nos interessarmos pelos determinantes dos padrões familiares (e não pelos pobres ou ricos como tais), então o estudo transversal desse problema nas classes sociais, ou pelo menos um estudo com um corte vertical, seria uma maneira de testar hipóteses como se certos aspectos 
da situação da classe baixa ou da classe alta são ou não, de alguma forma, o resultado de um tipo específico de padrão familiar (serialmente monogâmica, matrifocal, absenteísmo paternal), ou se a pobreza, por exemplo, é ou não gerada por certos tipos de padrões de emprego ou fatores externos. Ao menos colocar os problemas em um quadro comparativo ajudaria a melhorar nossas chances de entender as forças que geram excessiva pobreza ou excessiva afluência e as origens dessas forças, se elas provêm ou não da sociedade em geral ou se são "determinadas pela transmissão cultural dentro do grupo". Dependendo da visão da nossa visão dos processos que geram o comportamento, buscaríamos soluções para os problemas sociais, seja por meio de uma política voltada para a reforma da sociedade como um todo, seja por meio de uma política que vise modificar o comportamento da subcultura, ou ambos (GLADWIN 1969; VALENTINE, 1969).

Com base em tal trabalho em nossa própria sociedade ${ }^{1}$, poderíamos reescrever os livros sobre a American Society, cujos índices não mencionam os setores de propaganda, seguros, bancos, imóveis ou a indústria automobilística, que a maioria das pessoas na rua sabe que desempenharam um importante papel na formação da sociedade americana moderna. Os relatórios etnográficos descreveriam as empresas de comunicações, as agências que as regulam, as instituições que sustentam o setor industrial, tais como os órgãos legislativos, as universidades e organizações profissionais, e tais descrições seriam do ponto de vista dos usuários, bem como dos administradores. É apropriado que uma antropologia reinventada estude instituições poderosas e organizações burocráticas nos Estados Unidos, pois tais instituições e seus sistemas de rede afetam nossas vidas e também afetam a vida das pessoas que os antropólogos tradicionalmente estudaram em todo o mundo.

É particularmente apropriado que antropólogos liderem esse trabalho em virtude de uma série de características da nossa disciplina. O estudo do homem teve de ser eclético em seus métodos, amplo em sua visão do que é preciso para entender o homem - seu passado, seu presente, sua cultura, sua

Ver o livro Social Changes in Modern India, de Misori Narasinhachar Srinivas, capítulo 5: "Alguns pensamentos sobre o estudo de sua própria sociedade", para uma discussão dos problemas envolvidos em tal esforço. 
biologia. Nós nos especializamos em compreender culturas inteiras em um contexto intercultural. Deveríamos, por exemplo, nos sentir à vontade ao estudarmos o escritório de advocacia como uma sociedade secreta, ao encontrarmos e analisarmos as redes de poder - que no papel podem não existir ao descrevermos os comportamentos habituais não escritos que são totalmente indispensáveis para a compreensão de, por exemplo, o que faz o Congresso funcionar. O antropólogo deveria, acima de tudo, em virtude de sua compreensão do princípio da reciprocidade, ser capaz de analisar porque as decisões do pessoal da Federal Communications Commission podem não ser "racionais", ou as dimensões culturais envolvidas no fracasso dos programas nacionais ostensivamente voltados para a reintegração da sociedade. É o antropólogo que, em virtude de seus valores populistas, pode ser capaz de definir o papel do cidadão-erudito - uma ciência do homem para o homem.

\section{RELEVÂNCIA DEMOCRÁTICA}

"Estudar os de cima" parece ser um caminho para integrar preocupações sociais primordiais com os objetivos e metas da ciência do homem. O serviço que realizamos no passado poderia ser ampliado para incluir outro serviço, tanto social quanto científico, ou seja, escrever etnografias para os "nativos". Uma monografia que deve ser levada em conta pelos administradores em benefício das pessoas envolvidas é o recente livro de Elisabeth Colson, The Impact of the Kariba Resettlement upon the Gwembe Tonga (1971).

Desenvolvimento tecnológico pesado prejudica. Este é um fato amplamente ignorado pelos planejadores econômicos, técnicos e líderes políticos. Ao planejar drásticas mudanças no ambiente que desarraigam populações ou impossibilitam ajustes antigos, eles contam os custos de engenharia, mas não os custos sociais. Afinal, eles não pensam em si mesmos pagando esses últimos. Este livro é um estudo sobre o impacto da mudança forçada sobre algumas de suas vítimas (COLSON, 1971, tradução nossa). 
Outro exemplo é o livro de Spradley, You Owe Yourself a Drunk (1970), uma descrição etnográfica da interação e das consequências da interação que os bêbados têm com os sistemas jurídico e de segurança pública. Essa monografia já está servindo para educar os administradores desse sistema sobre as consequências de decisões e procedimentos legais específicos. Esse não é um papel novo a ser desempenhado pelos cientistas sociais e infelizmente nossas descobertas muitas vezes serviram para ajudar a manipular em vez de ajudar aqueles que estudamos. Outro papel, no entanto, está relacionado ao conceito de cidadania em um país que deve ser governado dentro de uma estrutura democrática e o controle que os cidadãos devem ter para aproveitar a manipulação administrativa. Nós não podemos, como cientistas responsáveis, educar os "administradores" sem educar os que estão "sendo administrados". Uma estrutura democrática implica que os cidadãos devem ter acesso aos tomadores de decisão, instituições governamentais e assim por diante. Isso implica que os cidadãos precisam saber algo sobre as principais instituições, governamentais ou não, que afetam suas vidas. A maioria dos membros de sociedades complexas e, certamente a maioria dos americanos não sabem suficientemente a respeito, nem sabem como enfrentar as pessoas, instituições e organizações que mais afetam suas vidas. Acredito que os antropólogos seriam surpreendentemente bons aplicando suas ferramentas descritivas e analíticas a um grande problema: como podem os cidadãos atuar em uma democracia quando eles lamentavelmente ignoram como a sociedade funciona e como não funciona, como um cidadão pode se "ativar" como tal: ou o que aconteceria se os cidadãos começassem a exercer outros direitos além do voto como forma de fazer o "sistema" funcionar para eles? Mas primeiro, como sabemos, temos de descrever a burocracia e sua cultura.

Love e Eaton (1970) iniciaram o estudo da Bay Area Air Pollution Control Agency com perguntas sobre as funções da agência: como a agência percebe a si mesma? Quem a usa? Como os usuários percebem a agência? O acesso público foi uma questão fundamental.

Nossa abordagem foi, inicialmente, cautelosa devido a nossas dúvidas. Fingimos inocência e, de fato, descobrimos que éramos realmen- 
te inocentes. Começamos então a perceber que estávamos "por fora". Nós éramos o público que não entendia a linguagem profissional sendo falada. As vias que abordávamos eram aquelas que o público geralmente abordava. Gradualmente, uma imagem da agência e sua posição no sistema jurídico surgiram.

Sua estrutura, as personalidades dos tomadores de decisão, as limitações que a realidade impõe a qualquer sistema ideal, e, por fim, as maneiras como a agência era usada se tornaram mais claros. (LOVE; EATON, 1970, p. 2-3, tradução nossa).

Quando vai à agência, o cidadão é transformado em dados estatísticos que o separam do procedimento ou uso real da agência. Parte-se do seguinte pressuposto: como a agência deve atuar para proteger o interesse público, o público vai procurar acessá-la. A realidade da situação é bastante diferente. A agência atua da maneira mais autônoma quanto possível no combater à poluição atmosférica e, ao fazer isso, estabelece um contato próximo com os dirigentes das indústrias que falam a mesma linguagem técnica e jurídica. É a indústria que tem o maior acesso à agência, especialmente em nível legislativo. É a indústria que faz o maior uso da agência para proteger seus interesses (LOVE; EATON, 1970, p. 32-33, tradução nossa).

Esse mesmo estudo observa que, no departamento jurídico da agência, autos de infração são tratados como multas de estacionamento proibido depois de muitas serem emitidas, o infrator é processado. Mas em que consiste o processo diante do padrão de interação social descritos acima? Não se tratava de criminosos comuns.

No departamento jurídico, o advogado da agência enfatizava que os princípios do direito penal não eram uma solução, daí as sanções civis. O funcionário "responsável" não merece ser preso com "prostitutas e assaltantes" por causa do tipo de "crime" cometido. Uma interessante observação em relação a esse procedimento é que o Regulamento 1, que não se aplica à maioria das grandes indústrias, mas a cidadãos e empreiteiros, é tratado como uma contravenção onde o infrator pode ser preso com "prostitutas e assaltantes" (LOVE; EATON, 1970, p. 33, tradução nossa). 
Além de ser um relatório útil sobre a cultura burocrática, esse relatório de 37 páginas é o tipo de informação etnográfica que os cidadãos precisam ter antes d tentar ganhar acesso a uma agência pública, ou tentar usá-la. Relatórios desse tipo os apresentariam à estrutura e à cultura do subgrupo de maneira a permitir avaliar se há ou não alguma parcialidade no processo, e a favor de quem, em termos de acesso real e de uso de uma agência pública.

O estudo do California Department of Insurance, e especialmente o processamento de reclamações pelo Policy Services Bureau dessa agência, é outra tentativa de descrever o funcionamento de uma organização cujos atos de omissão ou comissão afetam a vida de muitos (SERBER, 1971). Serber (1971, p. 62, tradução nossa) conclui que o Departamento de Reclamações não atende às necessidades das pessoas do Estado da Califórnia porque "a grande maioria das pessoas não tem consciência de sua existência”. Ele acrescenta, por meio de uma citação, uma visão adicional que tem sido observada por estudos de outros estudantes de agências governamentais (e não é muito diferente para agências privadas que pretendem servir ao público) e que sugere que tais instituições públicas não são estruturadas para acesso público:

É muito pior lidar com alguém do público, pois você sabe que as respostas que você pode dar e os resultados que você pode obter para essas pessoas são muito limitados. Eles esperam mais e muitas vezes ficam impacientes. Com a indústria, é diferente: eles são geralmente amigáveis e polidos, pelo menos na nossa frente; nós sempre sabemos onde estamos pisando e até onde podemos ir. É menos estressante porque eu me sinto menos responsável pelo resultado das conversas (Funcionário da Agência III apud SERBER, 1971, tradução nossa).

O relatório prossegue observando que "há uma diferença qualitativa na natureza da interação entre os reclamantes e o funcionário da agência e os representantes da indústria e o funcionário da agência”.

Não é muito agradável chegar aqui às oito horas da manhã depois de uma batalha para atravessar a Bay Bridge por quarenta e cinco minutos e antes de terminar uma xícara de café, uma megera gorda e histérica que mal consegue falar de tão burra e exaltada vai entrar e eles 
vão me chamar. Quando a vejo, meu estômago se contrai e minha boca fica seca; algumas vezes a queimação na minha garganta começa antes mesmo de eu poder ir até a mesa, e eu tenho que ir tomar um gole de água (Oficial de Seguros IV apud SERBER, 1971, tradução nossa).

Esse mesmo relatório faz um conjunto de previsões sobre o que poderia acontecer com esse Departamento de Reclamações se o acesso ao público fosse facilitado; a estrutura e a função do departamento se alinhariam mais com um dos principais objetivos do Departamento de Seguros: "aplicar as leis relativas a seguros a fim de alcançar o mais alto grau de proteção possível para o público em geral e todos os segurados e beneficiários em particular” (SERBER, 1971, p. 64).

O objetivo acima mencionado levanta uma questão mais geral: quem deve decidir o que é bom para o público? O artigo de Eaton sobre o BBB, de Oakland, ilustra o dilema de um conflito de valores.

Uma limitação importante no valor do BBB para o consumidor reside no próprio fato de ele ser uma organização projetada para promover os interesses de negócios legítimos. O movimento supõe que o que é bom para os negócios é bom para a economia e para o consumidor, que o poder da consciência e o poder da opinião pública triunfarão sobre o lucro desenfreado, que um público informado será capaz de moldar o mercado sensível aos seus próprios desejos. Essas suposições podem ser verdade em alguns níveis, mas o quadro não é tão simples. Existem áreas da sociedade nas quais o poder está concentrado e áreas onde ele está disperso ou totalmente ausente. A reclamação do consumidor tem mais peso com o varejista localmente competitivo do que com a corporação distante que fez o produto vendido pelo varejista. O Bureau regula a publicidade no varejo, mas o consumidor também está exposto à publicidade nacional, especialmente na televisão. $O$ varejista não é um agente livre: ele é limitado pelo distribuidor e pelo fornecedor.

O Bureau está preocupado com a verdade na publicidade, mas está igualmente preocupado com a relevância da publicidade? Há muitas coisas verdadeiras que podem ser ditas sobre um produto, mas que têm muito pouco a ver com seus atributos significativos: durabilidade, segurança, eficiência. Diz-se ao consumidor, por um lado, que é sua responsabilidade ser informado e exercer o seu poder de escolha 
para alinhar o mercado com as suas necessidades e desejos. Por outro lado, ele é atacado pela publicidade nacional, que enfatiza os atributos não utilitários dos produtos, e ele é confrontado com uma gama de produtos de diferentes fabricantes que essencialmente não diferem em áreas que o consumidor possa achar significativas. Ao consumidor, é dito que ele deve entender a garantia que vem com seu carro novo, mas não é dito o que ele pode fazer caso não goste dos termos e condições e descubra que todas as garantias de todas as empresas são iguais. Como indivíduo, ele basicamente não tem o poder de barganhar no maior sistema de mercado mais amplo que caracteriza a complexa sociedade moderna (EATON, 1971, p. 68-70, tradução nossa).

Entender as diferenças nas percepções dos produtores, de um lado, e dos consumidores, de outro, permite que um cidadão avalie por si mesmo qualquer declaração do governo sobre a necessidade de o governo não se intrometer nas organizações autorreguladoras, como o BBB, que são criadas por grupos empresariais. O estudo de Eaton (1971) sobre o BBB toca apenas uma pequena parte das tentativas de autorregulação dos negócios. Desde 1966, desenvolveu-se toda uma série de "mecanismos de tratamento de reclamações", desde "linhas diretas" até ouvidorias empresariais. Um estudo comparativo de tais mecanismos seria uma contribuição muito necessária para a literatura sobre a natureza das tentativas extrajudiciais de expressar reclamações e obter reparação. Seria fascinante saber até que ponto a "lei informal" é dominada por relações públicas e as técnicas publicitárias da Madison Avenue na administração de conflitos. O uso da publicidade na resolução de queixas pode estar relacionado a uma percepção das classes mais altas que diz: "Deixe esfriar ao invés de resolver".

Há alguns anos, o criminologista Edwin H. Sutherland (1949) escreveu um livro intitulado White-Collar Crime. Uma descoberta documentada nesse trabalho que se tornou um ponto de referência foi o simples fato de o pessoal do colarinho branco cometer crimes, algo que deveria ter ajudado a combater a crença, pelo menos entre os cientistas sociais, de que os pobres detinham o monopólio da criminalidade. Se, como cientistas, estamos interessados em compreender os determinantes do crime, então a "descoberta" de que tanto os ricos quanto os pobres cometem "crimes" (algo que é de conhecimento do cidadão comum, 
bem como, certamente, dos pobres) é muito importante. O fato de os crimes serem estigmatizados e processados diferentemente de acordo com a classe social deveria nos levar a desconsiderar teorias muito simplistas que explicam o comportamento criminoso. Pouquíssimos trabalhos sociológicos desse tipo seguiram o estudo de Sutherland e, de fato, houve um longo período de seca entre a investigação desses problemas na virada do século e Sutherland.

Em vez disso, sociólogos como Lewis Coser (1968) preferem nos dizer porque alguns pobres cometem e porque alguns pobres não cometem crimes em termos da teoria do comportamento criminal. Se olharmos para a questão em relação a uma fatia vertical, é um fato bem conhecido que o direito penal foi orientado para crimes individuais, preferencialmente crimes de rua, ao passo que o comportamento criminoso coletivo por parte de uma agência ou de uma empresa costuma ser tratado em órgãos administrativos ou de maneiras que estigmatizem muito pouco os envolvidos (POUND, 1906; SUTHERLAND, 1949). No entanto, nossa base de dados analisada é pequena. Henry Ruth, diretor do Institute of Law Enforcement and Criminal Justice, observou já em 1970, que:

o Institute of Law Enforcement and Criminal Justice demonstrou uma intensa preocupação para que o chamado "crime do colarinho branco" recebesse pouca atenção dos agentes da lei e dos pesquisadores. Todo o campo do crime do colarinho branco representa uma prioridade nacional de ação e pesquisa - para que se defina o problema, se examinem suas muitas faces, se meça seu impacto, se procurem formas de ajuda para vítimas e para que se determine como tal crime pode ser prevenido, dissuadido, e efetivamente processado (EDELHERTZ, 1970, p. iii, tradução nossa).

No que diz respeito ao benefício para os cidadãos, é surpreendente que em um país tão legalista quanto os Estados Unidos, não seja possível obter em lugar algum do sistema educacional o conhecimento prático da lei como parte da educação geral. De fato, depois de anos estudando o sistema jurídico zapoteca de Oaxaca, no México, eu concluiria que a única diferença mais importante entre o sistema jurídico zapoteca do sul do México e o sistema jurídico americano (do ponto de vista de uma classe média consumidora) é que os zapotecas têm acesso ao sistema jurídico e sabem como usá-lo. Nos Estados Unidos, 
a maioria dos cidadãos não tem acesso ao sistema jurídico, seja porque são ignorantes sobre o funcionamento do sistema, seja porque não podem pagar o profissional (advogado) com um conhecimento adequado do funcionamento do sistema. Na Califórnia, por exemplo - e imagino que isso seja muito mais amplo - há poucos livros para os cidadãos descrevendo o sistema jurídico, do que se trata e como funciona.

Essa situação é representativa do maior problema da educação cidadã. A maior parte do que aprendemos sobre direito é absorvida indiretamente de programas de TV sobre o faroeste e séries de TV do tipo Perry Mason ${ }^{2}$. Os trabalhos etnográficos sobre o direito preencheriam uma necessidade científica e descritiva, bem como informariam o nativo sobre um sistema que às vezes pesa muito na direção que sua vida toma. Por exemplo, um estudante iniciou um estudo sobre o Immigration and Naturalization Service (INS) em um esforço para descobrir como a imigração e o INS moldaram e influenciaram as comunidades de imigrantes do terceiro mundo. A hipótese básica era de que o INS é o produto histórico das atitudes americanas negativas em relação aos imigrantes que não são do norte da Europa - medo de estrangeiros, antipatia por culturas estranhas, isolacionismo e afins - e embora tenha havido uma grande liberalização das leis, a administração da imigração e, de fato, o recrutamento para a agência, continuam a ser afetadas por essas atitudes históricas. Outros estudos antropológicos podem envolver o uso de documentos pessoais - as memórias de juízes, advogados e executivos estão notadamente ausentes das estantes de livros. Os escritórios de advocacia de Washington, cujas funções de lobby ganharam o rótulo de quarto poder do governo, seriam um lugar fascinante para testar algumas das hipóteses de Elizabeth Bott (1957) sobre redes. Que formas e funções as redes desses escritórios têm em uma organização na qual, no meio da carreira, a maioria dos membros dessas firmas assume cargos por toda Washington, mas ainda mantém relações com o escritório de advocacia

\footnotetext{
Perry Mason foi uma série de televisão exibida nos Estados Unidos pela CBS entre os anos 1950 e 1960. O programa era sobre um advogado que defendia acusados de assassinato e sempre solucionava todos os casos (N. do T.).
} 
mesmo depois de não estar mais na folha de pagamento? Que tipo de reciprocidade está envolvida aqui?

\section{OBSTÁCULOS E OBJEÇÕES}

Mas há aqueles que não gostariam de cogitar qualquer reorientação da antropologia, e é importante apreciar as razões pelas quais os antropólogos atuais diriam “impossível”, "improvável”, "irrelevante”, "fora da meta”, até mesmo "impertinente”. Os obstáculos que são apresentados são muitos, mas para nossos propósitos aqui, podem ser discutidos em termos de acesso, atitudes, ética e metodologia.

Em geral, os departamentos de antropologia acreditavam que os alunos deveriam fazer seu trabalho de campo de dissertação em uma cultura não-ocidental. Em alguns momentos, essa era uma política útil a ser implementada caso, na formação dos antropólogos, fosse valorizada a importância do choque cultural e do distanciamento que o acompanha. Para muitos estudantes hoje em dia, a experiência de trabalhar em um escritório de advocacia de Washington, em uma vila operária ou em um complexo industrial internacional seria mais bizarra do que qualquer coisa que um antropólogo em formação pudesse encontrar em um vilarejo mexicano ou na Nova Guiné. Nós, antropólogos, estudamos as culturas do mundo apenas para descobrir, no final, que a nossa é uma das culturas mais bizarras de todas, que em virtude de sua influência mundial para o "bem" ou para o "mal”, precisa ser urgentemente estudada.

O obstáculo mais comum é fraseado em termos de acesso. Os poderosos estão fora de alcance em vários planos diferentes: eles não querem ser estudados; é perigoso estuda-los; eles são pessoas ocupadas; eles não estão todos em um só lugar, e assim por diante. Como alguns dos nossos alunos descobriram em seus estudos do uso corporativo dos tribunais:

A crença de que as corporações trabalham secretamente e sub-repticiamente a favor de seus próprios interesses foi até certo ponto comprovada. O desejo de sigilo, o medo paranoico de qualquer publicidade que não seja controlada por elas mesmas, a recusa em discutir 
questões sobre o seu funcionamento e o respeito excessivo de seus advogados pela natureza confidencial da relação advogado-cliente (mesmo quando os interesses do público estão em jogo), servem para eliminar qualquer fluxo livre de informações eventualmente disponíveis para a opinião pública, e nos fazem pensar nas antigas sociedades secretas. A furtividade das corporações é simbolizada por aqueles astutos mestres enxadristas que elas empregam para cuidar de suas causas, os advogados empresariais (ZEFF; BUSH, 1970, tradução nossa).

Essas dificuldades realmente se aplicam às pessoas que os antropólogos estudaram em muitos lugares diferentes. $\mathrm{O}$ fato de os problemas de acesso serem diferentes, ou pelo menos mais complexos, ao estudar os de cima nos Estados Unidos é uma proposição que não foi adequadamente testada. Os antropólogos tiveram problemas de acesso em todos os lugares onde passaram; solucionar tais problemas de acesso é parte do que constitui "criar entrosamento". Em vista do nosso êxito entre povos do mundo que foram incrivelmente hostis, é bastante surpreendente que os antropólogos sejam tão tímidos em seu próprio local de origem (ver RIESMAN, 1954, p. 44-66). Ademais, pode-se argumentar que o acesso a organizações burocráticas (como agências governamentais) frequentadas por ricos e poderosos deveria estar aberto a cientistas sociais por leis de salvaguarda do acesso público a informações que afetam o interesse público. Além disso, existem antropólogos ricos que presumivelmente teriam acesso aos "de cima". Cleveland Amory (1947) e E. Digby Baltzell (1964) deram contribuições substanciais para a compreensão do poder da classe alta, embora nenhum deles seja antropólogo. Não, deve haver razões mais plausíveis para que os menos poderosos sejam mais atraentes em termos de estudos nos Estados Unidos.

Já foi dito que, para os antropólogos, é importante estudar o que gostam e gostar do que estudam e, em geral, preferimos os mais desfavorecidos. Braroe e Hicks (1967), discutindo a mística da antropologia, fazem referência novamente à alienação tradicional de sua própria cultura que caracteriza os antropólogos, e exploram como essa alienação está relacionada à sua falta de intenso compromisso com a reforma social. Isso poderia ser formulado de forma mais positiva: os antropólogos favoreceram o estudo de culturas não-ocidentais como uma forma de cumprir sua missão de estudar os diversos caminhos da 
humanidade; não tiveram um intenso compromisso com reforma social por causa de sua postura relativista e pela crença de que tal postura era necessária para uma verdadeira "perspectiva científica objetiva e distanciada", ou porque pensavam que outros, como os sociólogos, estavam envolvidos com a reforma social. Embora as descobertas científicas possam ser vistas idealmente como "livres de valores", certamente a escolha dos temas da investigação científica certamente não o é. Os antropólogos do futuro terão uma responsabilidade maior pelo tema que escolherem estudar, bem como pela maneira de estudar.

Os problemas éticos levantados ao estudar os "de cima" quase sempre parecem ser confundidos, especialmente quando se discute a ética de trabalhar na própria sociedade. Um estudante fez o seguinte comentário:

Dizer que os participantes do circuito kula não realizam na prática o que eles dizem que fazem, tem consequências muito diferentes do que dizer que uma agência do governo não está cumprindo suas normas. Isso não quer dizer que a agência do governo não deve ser estudada, ou que o fato de não estar de acordo com suas normas não deva ser apontado. A questão é: o antropólogo pode fazer um estudo estrutural e depois, em seu papel de cidadão, apontar que a agência está prejudicando o público americano?

O mesmo estudante perguntou:

Como podemos ter acesso aos mesmos tipos de informação de quando "estudamos os de baixo" sem sermos desonestos (ou seja, um falso secretário ou outro papel)? Se conseguíssemos informações sem deixar que os informantes soubessem que éramos cientistas sociais, como poderíamos publicá-las? Parece que a única forma "aberta" de fazer um estudo acabaria sendo bastante superficial - questionários e entrevistas formais em contraponto ao que aprendemos da observação participante.

Os problemas levantados por esse estudante são problemas éticos que os antropólogos têm tiveram de enfrentar, a despeito da cultura que estivessem estudando. Ao discutir tais questões éticas envolvidas no estudo dos de cima em nossa própria sociedade, tenho a impressão de que a confusão surge do fato 
de reconhecemos ou não o uso implícito de dois pesos e duas medidas - existe uma ética para estudar os de cima e outra para estudar os de baixo? Ou será que, sugere este estudante, as consequências de descrever eventuais inadequações sistêmicas podem ser maiores para agências governamentais do que para sistemas econômicos camponeses ou para resolução de conflitos (ou simplesmente conflitos) em uma pequena vila de pescadores, e que, portanto, nossos sujeitos de estudo deveriam ser tratados de acordo?

Há uma importante distinção a ser reconhecida entre "público" e "privado", embora o anonimato do informante possa ser importante para ambos os setores. Em sua maioria, pode-se dizer que os antropólogos que trabalham nos Estados Unidos trabalharam na esfera "privada": estudamos famílias, pequenos grupos, aqueles aspectos das comunidades que são mais privados do que públicos. Não deveríamos necessariamente aplicar a mesma ética desenvolvida para estudar o privado, nem mesmo a ética desenvolvida para estudar em culturas estrangeiras (onde somos hóspedes), para o estudo de instituições, organizações, burocracias que têm um amplo impacto público. Ao reinventar a antropologia, qualquer discussão sobre ética deve considerar as dimensões público-privadas, bem como o componente doméstico-externo. Ademais, na atual antropologia, o trabalho considerado na modalidade objetiva da ciência social, quando realizado no exterior, poderia ser chamado de “jornalístico" pelos sujeitos. Falar explicitamente de algo pode ser entendido como uma "lavação de roupa suja" pelos sujeitos do estudo (o trabalho de Oscar Lewis sobre o México foi assim visto) ou por colegas profissionais que se sentem mais à vontade se os dados forem apresentados no jargão das ciências sociais que protegeria o trabalho do consumo comum.

O conceito de observação participante desempenha um papel determinante naquilo que os antropólogos escolhem estudar. O poder da observação participante como tal só foi descoberto no século XX. Malinowski e RadcliffeBrown, entre os primeiros a fazer o trabalho de campo segundo as técnicas da observação participante, estabeleceram um novo padrão para as descrições etnográficas. Quando um antropólogo vai estudar a cultura de um povo, ele vive com tal povo; a descrição resultante é rica em informações contextuais 
e é o resultado dos vários pontos de vista para os quais o pesquisador se abre por "estar vivendo com os nativos". Hortense Powdermaker (1966, p. 287) descreveu os componentes da observação participante da seguinte forma: "As condições para uma comunicação mútua bem-sucedida incluem 1) proximidade física do trabalhador de campo com as pessoas que ele estuda; 2) conhecimento do idioma; e 3) envolvimento psicológico".

Em seguida, ela afirma:

A capacidade de ser psicologicamente flexível é importante em situações hierárquicas onde é necessário deslocar-se facilmente entre diferentes níveis na estrutura de poder. Alguns trabalhadores de campo se identificam tão completamente com os desfavorecidos, que são incapazes de fazer contatos efetivos com aqueles no nível superior da hierarquia social (ou política) (POWDERMAKER, 1966, p. 291, tradução nossa).

Ao mesmo tempo em que descreveu o valor da observação participante, Hortense Powdermaker também mencionou as limitações de uma aceitação tão completa da observação participante como uma característica distintiva de todo trabalho de campo social antropológico. Quando o antropólogo participante observa, ele ou ela reside e geralmente convive com os "nativos". Tal método pesou muito nas decisões sobre onde os antropólogos conduzem seus estudos: nós preferimos situações residenciais, seja a residência em uma aldeia primitiva ou em um hospital moderno.

Até que ponto nossas escolhas de campo podem ser determinadas pela possibilidade de atuarmos ou não como observadores participantes é algo que ficou claro para mim quando dois de meus alunos foram a Washington para estudar um escritório de advocacia que não queria ser estudado (embora membros individuais estivessem dispostos a cooperar de uma forma limitada). Como eles poderiam observar participativamente, se a empresa não os deixava entrar pela porta, e se eles não podiam observar participamente, como poderiam fazer antropologia? Essas questões, certamente, foram levantadas antes na antropologia e, quando os antropólogos as consideraram suficientemente importantes, superaram os problemas levantados. Servem de exemplo 
os estudos de cultura à distância que surgiram na Segunda Guerra Mundial, ou o trabalho de Elizabeth Bott (1957) em seu estudo sobre parentesco em Londres, baseado principalmente em entrevistas presenciais.

O argumento aqui é que há uma mística sobre a observação participante que tem seu valor, todavia, persiste o fato de que a imagem que o antropólogo de si mesmo é estilhaçada (FISCHER, 1969) caso ele não possa fazer observação participante, e a maioria dos estudantes geralmente não recebe treinamento nos tipos de técnicas necessárias para se trabalhar com problemas em ambientes não residenciais, como bancos, seguradoras, agências governamentais, indústrias eletrônicas e afins. Quantos antropólogos sabem como descobrir quem são os donos de uma cidade? Se Sol Tax estiver correto ao apontar que os antropólogos não estão trabalhando nos problemas mais relevantes do mundo hoje - como população, poluição e guerra - porque não podem atuar como observadores participantes de tais problemas em uma comunidade, então, ao reinventar a antropologia, podemos ter de rever o valor atribuído à observação participante, que nos leva a esquecer da existência de outros métodos (GUSSOW; TRACY, 1971) que são mais úteis para alguns dos problemas e situações que gostaríamos de investigar. O uso de documentos pessoais, memórias, pode substituir a participação antropológica em algumas áreas da cultura cuja compreensão requer longos anos de participação. Um aluno faz os seguintes comentários sobre a metodologia de campo:

Obviamente, o principal método de pesquisa do antropólogo, a observação participante, não é totalmente aplicável quando se está estudando uma agência governamental ou instituição de elite e sua interação com várias pessoas. Uma situação específica pode ser tratada, mas os dados seriam obtidos via de regra através da observação e não da participação. Podemos definir participação de duas maneiras. Segundo uma definição, dizer que o pesquisador é um participante significa que ele é capaz de interagir como um nativo na situação estudada e, portanto, é capaz de usar a si mesmo como um informante. A outra definição considera o participante de acordo com um status alcançado por alguém de fora, uma vez que ele é tratado como alguém de dentro. Idealmente, quanto mais íntima a aceitação, menos o participante/observador influenciará a situação que ele está observando e mais próximo ele estará do status de participante. Considerando essas duas definições, o termo "observador/participante" não 
poderia ser aplicável aos tipos de situações que o etnógrafo gostaria de estudar em instituições de grande porte, a menos que ele realmente se tornasse membro do grupo que está estudando. O termo "observador/participante" não se aplicaria verdadeiramente às técnicas desses pesquisadores, mesmo nas situações em que eu estava tentando satisfazer a condição ideal. Ao se estudar a própria sociedade, especialmente se tratando de uma complexa e altamente especializada e heterogênea, a questão é determinar os níveis de participação efetiva e o nível de impedimento à participação. Se o antropólogo vai contribuir para a compreensão das instituições que, de uma maneira complexa, afetam a vida de muitas pessoas, ele deve adotar uma abordagem metodologicamente eclética (SERBER, 1971, p. 5-6, tradução nossa).

Entrevistas de diversos tipos (formal/informal, presencial/telefone) foram usadas pelos meus estudantes. Documentos foram usados (NORTH AMERICAN CONGRESS ON LATIN AMERICA, 1976) - documentos de relações públicas, para entender a autoimagem preferida da organização, e documentos internos sobre a estrutura e estatísticas do trabalho planejado e realizado pela organização - todos úteis na descoberta de tendências e o que é considerado problemático pelos atores. É também importante o que Marian Eaton rotulou de "autoanálise" - uma consciência por parte do estudante de como ele, enquanto cientista social, é percebido, evitado, aculturado e descrito nos encontros velados e não tão velados com informantes e membros de organizações e afins cujo trabalho é lidar com pessoas de fora. Podemos ter que dar maior prioridade aos valores antropológicos tradicionais, como usar nosso conhecimento sobre os outros como um espelho para nós mesmos e permitir que as questões nos levem à metodologia (e não o contrário).

Talvez tenhamos de reordenar nosso conceito sobre de antropologia urgentemente. Certamente, deveriam ser as necessidades da humanidade para o estudo do homem a liderar o caminho.

\section{NOTAS}

Sou muito grata a Elizabeth Colson, Marian Eaton, Dell Hymes e Julio Ruffini por terem lido e criticado versões anteriores deste artigo. Marian Eaton 
merece reconhecimento especial por ter ajudado na pesquisa e edição destas páginas. Os estudantes de graduação que foram pioneiros em "estudar os de cima" merecem reconhecimento por sua visão, suas atitudes perseverantes, seu prazer em fazer etnografia das situações da vida cotidiana em casa e por tentar fazê-lo de uma maneira melhor do que a de costume. O físico Arthur Rosenfeld merece agradecimentos especiais pelo financiamento de dois estudantes de antropologia em um esforço inicial para estudar os de cima em Washington, DC, um esforço que levou à formulação de ideias para este artigo.

\section{NOTA DOS TRADUTORES}

Agradecemos imensamente à Laura Nader por aceitar nosso pedido de tradução para a língua portuguesa e pela sua disponibilidade em responder nossas dúvidas e questões. Somos gratos aos editores, em especial Lucía Eilbaum e Fabio Reis Mota, por aceitarem a proposta de tradução, e aos colegas antropólogos, que foram consultados pelos editores, por suas considerações em relação à tradução do título do artigo. Agradecemos a Marcello Lino por sua revisão atenciosa e comentários sobre o título. Wellington Santos ainda agradece ao seu orientador, Prof. Felipe Berocan Veiga, e ao Prof. Marco Antonio da Silva Mello, pela acolhida em seus grupos de pesquisa.

\section{REFERÊNCIAS BIBLIOGRÁFICAS}

1. ADAMS, Richard Newbold. Crucifixion by power: essays on guatemalan national social structure, 1944-1966. Austin: University of Texas Press, 1970.

2. AMORY, Cleveland. The proper bostonians. New York: E. P. Dutton, 1947.

3. BALTZELL, Edward Digby. The protestant establishment: aristocracy and caste in America. New York: Vintage Books, 1964.

4. BENEDICT, Ruth. The chrysanthemum and the sword. Boston: Houghton Mifflin, 1946. 
5. BOTT, Elizabeth. 1957. Family and social network: roles, norms and external relationships in ordinary urban families. London: Tavistock, 1957.

6. BRAROE, Niels Winther; HICKS, George L. Observations on the mystique of anthropology. Sociological Quarterly, Omaha, v. 7, n. 2, p. 173-186, 1967.

7. COLSON, Elizabeth. The impact of the Kariba Resettlement upon the Gwembe Tonga. Manchester: University of Manchester Press, 1971.

8. COSER, Lewis A. Violence and the social structure. In: ENDLEMAN, Shalom (ed.). Violence in the streets. Chicago: Quadrangle Books, 1968. p. 71-84.

9. EATON, Marian. An ethnography of BBB Oakland: one consumer's view. 1971. Trabalho de Conclusão de Curso (Graduação em Antropologia) - Department of Anthropology, University of California, Berkeley, 1971.

10. EDELHERTZ, Herbert. The nature, impact, and prosecution of white-collar crime. Washington, DC: US Department of Justice, 1970.

11. FELLMETH, Robert. Power and land in California: preliminary draft. Washington, DC: Center for the Study of Responsive Law, 1971.

12. FISCHER, Ann. The personality and subculture of anthropologists and their study of U.S. Negroes. In: TYLER, Stephen A. (ed.). Concepts and assumptions in contemporary anthropology. Athens, GA: Southern Anthropological Society, 1969. p. 12-17.

13. GELLHORN, Walter. When Americans complain. Cambridge, MA: Harvard University Press, 1966.

14. GLADWIN, Thomas. Culture and poverty: critique and counter-proposals, by Charles Valentine. Current Anthropology, Chicago, v. 10, n. 2-3, p. 185, 1969.

15. GUSSOW, Zachary; TRACY, George S. "The use of archival materials in the analysis and interpretation of field data: a case study in the institutionalization of the Myth of Leprosy as "Leper". American Anthropologist, Arlington, v. 73, n. 3, p. 695-709, 1971.

16. HANNERZ, Ulf. Soulside: inquiries into ghetto culture and community. Chicago: University of Chicago Press, 1969.

17. HENRY, Jules. Culture against man. New York: Random House, 1963.

18. KLUCKHOHN, Clyde. Mirror for man. Greenwich, CT: Fawcett, 1963.

19. LEACOCK, Eleanor Burke. The culture of poverty: a critique. New York: Simon and Schuster, 1971. 
20. LOVE, Norma; EATON, Marian. The Bay Area Air Pollution Control District: an anthropological perspective. Department of Anthropology, University of California, Berkeley, 1970. Trabalho de graduação não publicado.

21. MALINOWSKI, Bronislaw. Argonauts of the Western Pacific. London: Routledge, 1922.

22. MITCHELL, James Clyde. Theoretical orientations in African urban studies. In: BANTON, Michael (ed.). The social anthropology of complex societies. London: Tavistock, 1966. p. 37-68. (Association of Social Anthropologists Monograph, n. 4).

23. NADER, Laura. Perspectives gained from field work. In: TAX, Sol (ed.). Horizons of Anthropology. Chicago: Aldine Press, 1964. p. 148-159.

24. NORTH AMERICAN CONGRESS ON LATIN AMERICA. Research methodology guide. New York: Nacla, 1976.

25. POUND, Roscoe. 1906. The causes of popular dissatisfaction with the administration of justice. In: AMERICAN BAR ASSOCIATION CONGRESS, 29., 1906, Chicago. Reports [...]. Chicago: American Bar Association, 1906. pt. 1, p. 395-417.

26. POWDERMAKER, Hortense. Stranger and friend: the way of an anthropologist. New York: W. W. Norton \& Co., 1966.

27. RESEK, Carl. Lewis Henry Morgan: American Scholar. Chicago: University of Chicago Press, 1960.

28. RIESMAN, David. Individualism reconsidered and other essays. Glencoe, IL: Free Press, 1954.

29. SERBER, David. A discussion of the Policy Services Bureau of the California Department of Insurance, with specific reference to the interaction with the Insured public and the insurance industry. 1971. Trabalho de Conclusão de Curso (Graduação em Antropologia) - Department of Anthropology, University of California, Berkeley, 1971.

30. SPRADLEY, James P. You owe yourself a drunk: an ethnography of urban nomads. Boston: Little, Brown \& Co., 1970.

31. SRINIVAS, Mysore Narasimhachar. Social change in modern India. Berkeley: University of California Press, 1966.

32. SUTHERLAND, Edwin H. White-collar crime. New York: Dryden Press, 1949.

33. VALENTINE, Charles. Culture and poverty: critique and counter-proposals, by Charles Valentine. Current Anthropology, Chicago, v. 10, n. 2/3, p. 181-182, 1969. 
34. WEAKLAND, John H. "The double bind" hypothesis of schizophrenia and threeparty interaction. In: JACKSON, Don D. The etiology of schizophrenia. New York: Basic Books, 1960. p. 373-388.

35. WOLF, Eric. American anthropologists and American society. In: TYLER, Stephen. Concepts and assumptions in contemporary anthropology. Athens, GA: Southern Anthropological Society, 1969. p. 3-11.

36. ZEFF, David; BUSH, Peggy. Corporate use of the courts. Department of Anthropology, University of California, Berkeley, 1970. Trabalho de graduação não publicado. 